\title{
Design of Hydraulic Transmission Structure of Autostereoscopic Garage Xin $\mathrm{Su}^{1, a}$, Chunyu Mao ${ }^{1, b^{*}}$ and Sansui Liü \\ 1 Jilin Engineering Normal University, Changchun, China \\ a820675311@qq.com, b290414003@qq.com, ‘848824225@qq.com \\ *The Corresponding author
}

Keywords: Lift-and-slide stereo garage; Lift; Hydraulic; Motor; Sprocket

\begin{abstract}
The stereoscopic garage is one of the important ways to solve the parking problem, among which the application of the lift-and-push type stereoscopic garage is the most widely used. This article set the size of the parking space is $5200 \mathrm{~mm} \times 2500 \mathrm{~mm} \times 1600 \mathrm{~mm}$, the maximum parking quality of $1800 \mathrm{~kg}$, a total of two layers of the garage can be parked on three cars, the lower layer can park two cars, garage car plate lifting time 10s, lower load Car plate traverse time 10s. This paper analyzes the development direction of the transmission system, and completes the design of the autostereoscopic garage transmission system, including the lifting device design of the upper deck carriage of the three-dimensional garage, the selection of the hydraulic motor, the design of the hydraulic system, the design verification of the sprocket, and the transmission The design of the shaft is checked and the hydraulic transmission design of the lower traverse is adopted. The verified effect is good.
\end{abstract}

\section{Introduction}

The autostereoscopic garage is a new industry in China and has broad prospects for development. The lift-and-throw stereoscopic garage refers to a mechanical parking device that uses a vehicle plate to lift or laterally shift access to park the vehicle ${ }^{[1-3]}$. As shown in Fig. 1, the upper loading plate only moves up and down, and the lower loading plate only moves left and right. The size of the parking spot is $5200 \mathrm{~mm} \times 2500 \mathrm{~mm} \times 1600 \mathrm{~mm}$, and the maximum parking quality is $1800 \mathrm{~kg}$. The garage has a total of two layers. 3 cars can be parked, 2 cars can be parked in the lower level, the time for lifting the car in the garage is $10 \mathrm{~s}$, and the time for the lower deck to move $10 \mathrm{~s}$.
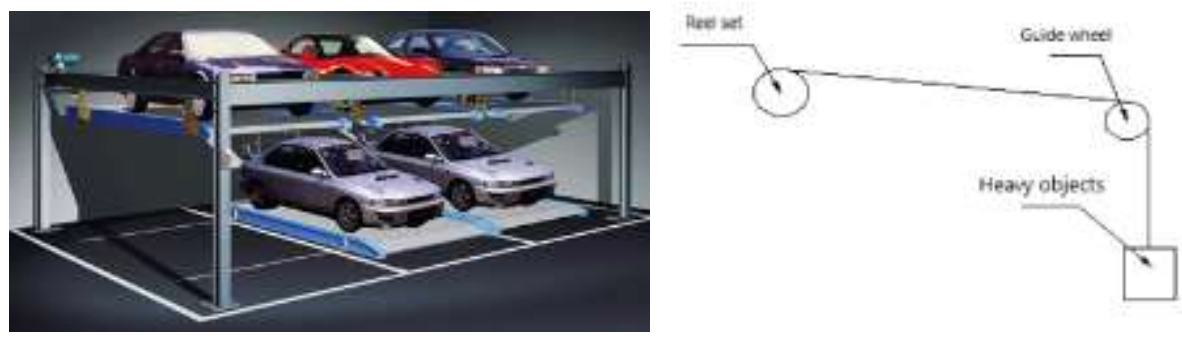

Figure 1. Finite Autostereoscopic garage structure diagram Figure 2. Finite Hoist working principle

Autostereoscopic Garage Hydraulic Drive System. The transmission system of the three-dimensional garage mostly adopts the mechanical transmission, while the hydraulic transmission is less. The biggest advantage of the hydraulic transmission in the automatic garage is that the noise is small, the work is relatively stable, the unit volume is light, and the automatic control is easy. Therefore, in the developed countries such as Europe and the United States, the autostereoscopic garage has developed into a hydraulic transmission system ${ }^{[4,5]}$. 


\section{Upper Deck Lifting Device Design.}

The upper deck is an important lifting device for lifting the vehicle from the ground to the upper deck and providing a safe and stable parking space. Therefore, the upper deck board uses reels, guide wheels, wire ropes and hydraulic motors to complete a series of lifting exercises ${ }^{[5,6]}$.

Lifting drive system design. According to the design need to select the reel and the lifting design manual selection T153 volume with the group, the parameter is $\mathrm{D} 0=300 \mathrm{~mm}$, the maximum lifting height is $5000 \mathrm{~kg}$, the lifting weight is $11.5 \mathrm{~mm}$, the matching selection of steel rope diameter is $\mathrm{A}$. When the carriage plate is lifted, the guide roller and the reel set need to be moved together to complete. as shown in picture 2:

Calculate the force acting on the drum;

The reel is subject to the weight of the car's weight and the friction force generated by the guide wheel. The friction coefficient $f=0.02$ between the steel rope and the guide wheel. Therefore:

$\mathrm{F}=\mathrm{F}_{\text {car }}+\mathrm{F}_{\text {load }}+\left(\mathrm{F}_{\text {car }}+\mathrm{F}_{\text {load }}\right) * \mathrm{f}=18000+6000+(18000+6000) * 0.02=28800 \mathrm{~N}$

Equation (1) is the force calculation formula for the reel set, where $\mathrm{F}$ is the force applied to the hydraulic motor. Therefore, the force applied by the hydraulic motor is $28800 \mathrm{~N}$. According to the hydraulic transmission and the air pressure transmission table, the hydraulic drive pressure is determined to be 5 MPA.

According to the hydraulic pressure transmission and control, the hydraulic motor has a simple structure, low noise and flow pulsation, and is suitable for occasions where the load torque is small, the speed is smooth and the noise requirements are high ${ }^{[7]}$. So select the blade hydraulic motor. The basic parameters of the hydraulic motor are: displacement $\mathrm{v}=154 \mathrm{ml} / \mathrm{r}$, speed $100 \mathrm{r} / \mathrm{min}$, and output torque $98 \mathrm{Nm}$. The hydraulic motor oil outlet is $0 \mathrm{Mpa}$ and the oil inlet pressure is $5 \mathrm{Mpa}$ and the pressure difference is $5 \mathrm{Mpa}$, so the hydraulic motor can directly return the oil to the oil tank.

As the lifting system uses a vane type hydraulic motor, the system achieves constant speed lifting. The height of the loading plate from the ground is $2 \mathrm{~m}$, and the hydraulic system completes the lifting (falling) process within 10 seconds; Therefore, the speed should be greater than:

$$
v=\frac{2}{10}=0.2 \mathrm{~m} / \mathrm{s}
$$

Equation (2) is the calculation formula for the vehicle speed.

Take the speed $\mathrm{v}=0.25 \mathrm{~m} / \mathrm{s}$, because the load plate and the wire rope connected, the wire rope and the drum connected, so the reel's linear speed is $0.25 \mathrm{~m} / \mathrm{s}$. Roll angular velocity $\omega$ :

$\omega=\frac{v}{r}=\frac{0.25}{0.3}=3.34 \mathrm{rad} / \mathrm{s}$

Formula (3) is the angular velocity calculation formula of the reel. Reel speed n:

$$
n=\omega t=3.34 \times 60=200 \mathrm{r} / \mathrm{min}
$$

Formula (4) is the calculation formula for the rotation speed of the reel. The hydraulic motor rotates at a speed of $100 \mathrm{r} / \mathrm{min}$, and the transmission system uses a sprocket transmission with a transmission coefficient $\mathrm{i}=2$. The flow rate of the hydraulic motor is:

$$
q=V n=154 \times 100=15400 \mathrm{ml} / \mathrm{min}=15.4 \mathrm{~L} / \mathrm{min}
$$

Formula (5) is the flow calculation formula of the hydraulic motor.

Due to the uncertainty of the piping layout of the hydraulic system, the total hydraulic circuit loss is approximately $5 \%$, and the flow loss is approximately $1 \%$. and so: $\mathrm{p}=5.12 \mathrm{Mpa}, \mathrm{q}=15.6 \mathrm{~L} / \mathrm{min}$

According to the above data, the hydraulic pump is selected, the flow rate is $25 \mathrm{~L} / \mathrm{min}, \mathrm{p}=6.3 \mathrm{Mpa}$, and the rotation speed is $\mathrm{n}=1000 \mathrm{r} / \mathrm{min}$. Because the hydraulic pump can not completely convert the motor drive, so the efficiency of the hydraulic pump to take $\eta=80 \%$, according to the above data on the hydraulic pump motor selection: 


$$
P=\frac{p q}{\eta}=6.3 \times 10^{6} \times 25 \times 10^{-3} / 0.8=3281 \mathrm{w}=3.21 \mathrm{kw}
$$

Formula (6) is the power calculation formula of the hydraulic motor, and the motor rated power is $4 \mathrm{KW}$, and the motor speed is $1000 \mathrm{r} / \mathrm{min}$.

Lifting Hydraulic System Design. According to the above parameters, the hydraulic system loop is designed. There is only one vehicle at a time in the garage for lifting movements. After the lifting is completed, the control system can perform other movements ${ }^{[8]}$.

As shown in Fig. 3: 1 is a filter, 2 is a hydraulic pump, 3 is an adjustable flow valve, 4 is a direct-acting relief valve, and 11 is a hydraulic pressure gauge. 5,7,9 for the three-position four-way solenoid valve; 6,8,10 for the hydraulic motor; 1YA, 2YA for the No. 5 three-position four-way solenoid valve solenoid valve; 3YA, 4YA for the 7th three-position four-way Two solenoid valves of solenoid valve; 5YA, 6YA are two electromagnetic valves of No. 9 three-position four-way solenoid valve.


Figure 3. Finite Lifting hydraulic system working principle Figure 4. Finite Hydraulic schematic diagram of lower deck

Lifting Hydraulic System Sprocket Design. As the rotation speed of the transmission shaft is $\mathrm{v}=0.25 \mathrm{~m} / \mathrm{s}$, much less than $0.6 \mathrm{~m} / \mathrm{s}$, the chain transmission is a low-speed chain transmission. The sprocket's tensile strength is not strong enough to be damaged. Therefore, according to the mechanical manual on the sprocket row tensile strength calculations:

$$
S_{c a}=\frac{Q}{K_{A} F+F_{c}+F_{f}} \geq[S] \quad F_{c}=q v^{2} \quad \begin{aligned}
& F_{f}^{\prime}=K_{f} q a \times 10^{-2} \\
& F_{f}^{\prime \prime}=\left(K_{f}+\sin \alpha\right) q a \times 10^{-2}
\end{aligned}
$$

Formula (7) is the tensile strength calculation formula.

$\mathrm{S}_{\mathrm{ca}}$ in formula (7) is the calculated safety factor of the tensile static strength of the chain;

$\mathrm{Q}$ is the ultimate tensile load $(\mathrm{KN})$ for a single-row chain, $\mathrm{K}_{\mathrm{A}}$ is the work factor $1, \mathrm{~K}_{\mathrm{C}}$ is the tension caused by the centrifugal force, $0, \mathrm{~K}_{\mathrm{f}}$ is the vertical tension, and $\mathrm{K}_{\mathrm{A}}$ is the effective tensile coefficient of the chain 1.

Select the chain number according to the mechanical design;

The initial selection of the ISO chain number is $20 \mathrm{~A}$, with a pitch of $\mathrm{p}=35.76$, a row spacing of $\mathrm{p}_{\mathrm{t}}=35.76$, and a single row of tensile load of $86.7 \mathrm{KN}$. According to formula (7) is the tensile strength calculation formula: $S_{\mathrm{ca}}=3.01<[S]=6$.

The safety factor is too small to meet the requirements.

Reselect the ISO chain number $28 \mathrm{~B}$ with a pitch of $\mathrm{p}=44.54$, a row spacing of $\mathrm{p}_{\mathrm{t}}=59.56$, and a single row of tensile load of $200 \mathrm{KN}$.

According to equation (7) tensile strength calculation formula: $S_{\mathrm{ca}}=6.94<[S]=6$.

Its safety factor greater than 6 meets the requirements.

Since the chain speed is less than $0.6 \mathrm{~m} / \mathrm{s}, Z_{1} \geq 13$; so the number of teeth of the sprocket of the hydraulic motor is 14 teeth, the hydraulic motor and the transmission coefficient $i=2$; the parameter of the transmission shaft is 7 , and the transmission sprocket is determined.

Calculate the index circle diameter of the sprocket:

$d=\frac{P}{\sin }\left(\frac{180^{\circ}}{Z}\right)$ 
Equation (8) is the formula for calculating the pitch circle diameter of the sprocket; where $p$ is the sprocket pitch. According to formula (8) sprocket's index circle diameter calculation formula: $\mathrm{d}_{1}=199.76 \mathrm{~mm}, \mathrm{~d}_{2}=102.45 \mathrm{~mm}$.

Hydraulic motor sprocket indexing circle diameter $d_{1}=199.76 \mathrm{~mm}$; hydraulic motor sprocket indexing circle diameter $\mathrm{d}_{2}=102.45 \mathrm{~mm}$.

Lifting Hydraulic System Driveshaft Design. Transmission shaft selection $\Phi 60 \mathrm{~mm}$ seamless steel pipe, seamless steel pipe thickness $\delta$;

The length of the transmission shaft is that the coils are welded at the end of the transmission shaft and the sprocket is welded at the middle of the transmission shaft.

The force analysis is performed on the drive shaft, where the diameter of the spool is the diameter of the indexing aip? [e] of 6 thex sprocket.

$\delta \geq \frac{\left(\sqrt{\pi D^{3}[\tau]}\right)}{2}$

Formula (9) is a formula for calculating the wall thickness of a seamless steel pipe.

Among them $[\tau]=80 \mathrm{Mpa}, \mathrm{D}$ is the diameter of the seamless steel pipe, $\mathrm{T}_{\max }$ is the maximum torque of the hydraulic motor:

$$
T=\frac{P}{2 \pi n}=\frac{3281}{2 \pi \times 100}=522.2 \mathrm{~N} \cdot \mathrm{m}
$$

Formula (10) is the torque calculation formula of the sprocket. Substituting data into equation (9): $\delta$ $=2.87 \mathrm{~mm}$.

After the selection of $60 \mathrm{~mm}$ seamless steel pipe, the wall thickness is $5 \mathrm{~mm}$; the selected material is 45 steel.

\section{Traverse Hydraulic System Design}

The lower deck board moves laterally with a distance of $2.5 \mathrm{~m}$. The vehicle-carrying plate moves at a constant speed on the horizontal track of the ground $[9,10]$. The loading plate is driven by the hydraulic motors distributed on the front and rear guide wheels. The movement of the carriage plate on the guide rail only has to overcome the maximum friction between the guide roller and the guide rail:

$$
\mathrm{F}=\left(\mathrm{F}_{\mathrm{car}}+\mathrm{F}_{\text {load }}\right) *(18000+6000) * 0.01=240 \mathrm{nN}
$$

Formula (11) is the friction formula.

Where Fcar and $F_{\text {load }}$ are respectively the weight of the vehicle and the vehicle plate; $f$ is the friction coefficient $\mathrm{f}=0.1$; guide wheel diameter $\mathrm{D}=100 \mathrm{~mm}$; After calculating $\mathrm{M}=6 \mathrm{~N} \mathrm{~m}, v=\frac{2.5}{10}=0.25 \mathrm{~m} / \mathrm{s}$, $\omega=\frac{v}{r}=\frac{0.25}{0.05}=5 \mathrm{rad} / \mathrm{s}, \quad n=\omega t=5 \times 60=300 \mathrm{r} / \mathrm{min}$.

Hydraulic motor selection: The working pressure of the hydraulic motor is checked by hydraulic transmission and pneumatic transmission to determine the working pressure of $1 \mathrm{Mpa}$. A vane-type hydraulic motor was selected based on the above parameters, and its rotation speed was $300 \mathrm{r} / \mathrm{min}$, and the flow rate was $\mathrm{v}=93 \times 300 \mathrm{ml} / \mathrm{min}=27.9 \mathrm{~L} / \mathrm{min}$. Due to the uncertainty of the piping layout of the hydraulic system, the loss of the entire hydraulic circuit is about $5 \%$, and the flow loss is about $1 \%$; and so: $\mathrm{p}=1.05 \mathrm{Mpa}, \mathrm{q}=18.185 \mathrm{~L} / \mathrm{min}$. below.

Its hydraulic schematic diagram is similar to the principle of lifting carriage plate, as shown in Fig. 4 


\section{Summary}

This article has completed the design of the hydraulic system of the ascending structure and the traversing mechanism of the three-dimensional garage. For the future parking garage hydraulic drive system should lay a good foundation.

\section{References}

[1] Kwak H G, Song J Y. Live load design moments for parking garage slabs considering support deflection effect[J]. Computers \& Structures, 2001, 79(19):1735-1751..

Reference to a book:

[2] Yang C. On the Application and Development of Mechanical Three-Dimensional Garage[J]. Journal of Xian University of Arts \& Science, 2012.

[3] Jian-Feng L I, Duan W J, Fang B, et al. Three-dimensional Garage Scheduling Optimization Based on Improved Genetic Algorithm[J]. Control Engineering of China, 2010.

[4] Dai S, Bin L I, Shi Z, et al. Design on PLC Control Hydraulic Stereo Garage[J]. Machine Tool \& Hydraulics, 2006.

[5] Wang X. Design on Automatic Control System of Stereo-Garage Based on PLC[J]. Industrial Control Computer, 2005.

[6] Guo Y, Sui H M, Wen-Miao L I. Development of Automatic Stereo Garage System for Teaching Experiment[J]. Research \& Exploration in Laboratory, 2004.

[7] Zhou Q. Design for Automatic Stereo Garage System Based on PLC Control[J]. Guide of Science \& Education, 2018.

[8] Li C, Xie L. The design and implementation of Intelligent Stereo Garage simulation system[J]. Electronics World, 2018.

[9] Yunyue Y E. Aisle-stacking-type stereo garage driven by linear motor:, US 20170211286 A1[P]. 2017.

[10] Zhen-Zhu L I. The Application and Realization of Simulation Technology in Stereo Garage[J]. Management \& Technology of Sme, 2017. 